\title{
Quest for Timely Detection and Treatment of Women With Depression
}

\author{
Jeanne Leventhal Alexander, MD, FABPN, FRCPC, FAPA, FACPsych
}

\begin{abstract}
BACKGROUND: Women are at risk for a wide range of depressive and anxiety disorders and particularly for mood disorders associated with their menstrual cycle, with seasonality, and during the menopausal transition.

OBJECTIVE: To review the presentation of depression, the importance of timely and effective treatment, and some of the research surrounding increased prevalence of depression in women, and the times and conditions-such as the perimenopausal transition, pregnancy, postpartum period, and comorbidities—of this increased risk in women.

SUMMARY: Dynamic interactions of both biological and environmental factors contribute to the development of major depression. These include, but are not limited to, predisposing genetic influences, gender, environmental stressors, poor social support, childhood sexual abuse, other psychiatric illness, and trauma. Timely and effective treatment of each episode of depression to remission is critically important. Barriers to instituting collaborative care of depressive illness are numerous. The lack of adequate collaborative care along with the consequent failure to adequately diagnose and treat depression reflects some of the deficiencies in the current organization and delivery of health services.
\end{abstract}

CONCLUSION: The prevalence of depression, its psychosocial and medical consequences, and the worsening course of depression without treatment highlight the public health importance of early detection and improved strategies for the treatment of depression in modern health care settings.

J Manag Care Pharm. 2007;13(9)(suppl S-a):S3-S11

Copyright@ 2007, Academy of Managed Care Pharmacy. All rights reserved.

\section{Author}

JEANNE LEVENTHAL ALEXANDER, MD, FABPN, FRCPC, FAPA, FACPsych, is director, Psychiatry Women's Health Program, Kaiser Permanente Northern California, Oakland, and an adjunct assistant clinical professor of psychiatry, Stanford University Department of Psychiatry and Behavioral Sciences, Stanford, California. She is the founder and president, Alexander Foundation for Women's Health, a nonprofit organization in Berkeley, California.

AUTHOR CORRESPONDENCE: Jeanne L. Alexander, MD, FABPN, FRCPC, FAPA, FACPsych, Alexander Foundation for Women's Health, 1700 Shattuck Avenue, Suite 329, Berkeley, CA 94709.

Tel.: 510.527.3010; Fax: 510.525.3189; E-mail: Jeanne@afwh.org
$\mathrm{D}$ epression is a widespread, debilitating psychiatric illness with significant economic and humanistic consequences. It is common and can be quite serious in nature. ${ }^{1,2}$ Women carry a greater burden of affective and anxiety disorders than do men, with the lifetime prevalence of depression in women at about $21 \%$, compared with $13 \%$ in men. ${ }^{3}$ An analysis by the World Health Organization found that depression is the leading cause of health-related disability and that depression is the second leading cause of disease burden for women in the United States. ${ }^{4}$ Depression currently affects 20 million Americans and 19 million Europeans (in European Union countries), and the rates of depressive illness are increasing. ${ }^{5}$ The barriers to diagnosis, treatment, and achieving treatment to remission are numerous and represent a significant challenge to the health care system. ${ }^{6-8}$

\section{Effective Treatment Exists for Depression}

Although no clearly identifiable determinants exist, several theories have been proposed to explain the increased prevalence rate of depression in women. Adverse experiences as well as depression and/or anxiety disorders during childhood, along with gender differences in sociocultural roles, have been implicated. ${ }^{9-12}$ In studying the lifetime incidence of major depression in twin pairs, Kendler et al. found that the heritability of major depression was higher in women (42\%) than in men (29\%). Interestingly, girls and boys have equal prevalence rates until adolescence. ${ }^{13}$ However, after puberty, prevalence increases in girls until early adulthood, when women consistently have a higher prevalence of depression compared with men. ${ }^{14}$ Premenstrual dysphoric disorder (PMDD), with a 12-month prevalence of $3 \%$ to $8 \%$ of women, ${ }^{15}$ also contributes to the greater prevalence of depression in women.

\section{Depression Risk Factors}

Dynamic interactions of both biological and environmental factors contribute to the development of major depression. These include, but are not limited to, predisposing genetic influences, gender, environmental stressors, poor social support, childhood sexual abuse, other psychiatric illness, and trauma. . $^{14,16-19}$

\section{Past Depressive Episodes}

The greatest risk factor for a future depressive episode is a past depressive history. In 1 study, women who had a history of depression were nearly 5 times more likely to have a future episode of major depressive disorder. ${ }^{20}$ Risk of recurrence for depression in either gender has been found to increase with each episode: the first episode increases the risk of a second by 50\%; 2 episodes increase the risk of a third by $70 \%$; and 3 episodes increase the risk of a fourth by $90 \% .^{21-23}$ It has been shown that 
with each new depressive episode, the association between stressful life events (SLEs) and the onset of the next depressive episode becomes progressively weaker. ${ }^{24,25}$ Corruble et al., in their crosssectional survey of 13,377 treated patients with unipolar depression, found a linear reduction in the "average life events exposure" as a function of the frequency of depressive episodes of severity in the past ${ }^{26}$ consistent with the results of Kendler et al. ${ }^{24,25}$

\section{Stressful Life Events}

Two of the most widely replicated findings for major depression are its greater prevalence in women after adolescence and its causal association with SLEs. ${ }^{24,27}$ Bouma et al. found an increased association between adolescent females with a parent who had had a depressive episode (lifetime) and sensitivity to the depressogenic effects of SLEs compared with same-aged males, regardless of temperament, family functioning, and/or perceived parenting. ${ }^{28}$ Stress is an important predictor for the development of mood-continuum problems. ${ }^{18,19}$ Stressors have different effects on a woman depending on the nature of the stress, its duration, her early life experiences, her customary positive or negative bias toward appraising the stress, and her stage of life.

New research has found an association between some individuals who may be particularly vulnerable to SLEs and/or adverse environments and genetic polymorphisms of the serotonin transporter gene promoter region (5-HTTLPR) locus of the serotonin transporter (5-HTT) gene. ${ }^{29-31}$ Furthermore, the combination of polymorphisms of brain-derived neurotrophic factor, 5-HTTLPR, and maltreatment/SLEs have been associated with increased risk of depression with SLEs in both children ${ }^{32}$ and in the adult population. ${ }^{30}$ Wichers et al. recently reported on the effects of moment-to-moment effect of positive emotions on genetic risk for depression in a sample of 279 twin pairs. ${ }^{33}$ The genetic influence of SLEs on lifetime depression and the genetic effects on "negative mood bias" in daily life were found to be "buffered" by positive stress appraisal. Safford et al. concluded from their study appraising SLEs of 76 undergraduates with high negative cognitive styles compared with 81 undergraduates with low negative cognitive styles that the underlying cognitive style affects stress generation, particularly in women. ${ }^{34}$ These studies point to the importance of intervention early in life and the potential strategic impact of operationally based therapies, such as cognitive behavioral therapy and interpersonal psychotherapy, in depression risk as well as prevention for recurrence.

Women consistently report SLEs to be associated with housing problems, loss of confidence, proximal relationship problems, and illness of an individual in their distal network. ${ }^{35}$ Studies have found an association between a high-demand psychosocial work environment and depression risk/depressive disorders, ${ }^{36}$ burnout/emotional exhaustion, ${ }^{37}$ and/or malaise/fatigue. Marital stress and/or family stress, as well as demands along with high work stress, have been found to increase the risk of depression along with increased risk of other mental health problems. ${ }^{38}$
Women are often placed in the caregiving role with multiple caregiving responsibilities involving children, spouses, and parents. Maclean et al., in their cross-sectional data analysis of the Canadian National Public Health Survey of women aged 15 to 64 , found that distress, stress, and chronic stress levels were high for mothers, regardless of their employment or marital status. ${ }^{39}$ The levels were even higher if the mother was unemployed or single. Employment was helpful to the single mothers; however, in those mothers who had partners, employment was found to increase their stress. ${ }^{39}$

These studies on stress in women and the impact of stressors on a woman's risk of developing mood problems suggest multiple contributing factors. Thereby, some of the challenges for the health system are to create effective treatment plans to help these women improve their mood disorders, to decrease the effects of their underlying stressors, and to increase their positive cognitive appraisal skills for those underlying stressors. ${ }^{18,19,28,33,34}$

\section{Impact on Family and Social Network}

Depression not only affects the patients, it also adversely affects their family, friends, and caregivers. Females with mood disorders have been found to have higher odds of divorce, teenage pregnancy, and failure to complete high school than do those females without mood disorders. ${ }^{40}$ As women are frequently caregivers, the impact of depression has been found to have a carry-over effect on those receiving care. Children of depressed mothers are at increased risk of developing emotional and behavior problems. ${ }^{28,41}$ This link has been explained by both genetic (nature) and non-genetic (nurture) influences ${ }^{41} \mathrm{~A}$ growing body of evidence shows that children of women with depression have higher rates of school problems and lower levels of social competence and self-esteem than do their classmates whose mothers are not depressed. ${ }^{42}$

\section{Timely and Effective Treatment}

The barriers to improving care of depressive illness are well known. Patients may resist mental disorder diagnoses or fail to follow up with prescribed treatment for reasons including side effects or unawareness of long-term benefits. ${ }^{43}$ Primary care practitioners have low rates of diagnosing depression, of prescribing according to guidelines recommended by the American Psychiatric Association, and of following up with patients after treatment is initiated. ${ }^{23,44}$ Health care systems have had difficulty instituting effective systems to deliver care to depressed patients in the primary care setting. ${ }^{8}$ The problem appears not to be the lack of effective treatments for depression but structural deficiencies in many health care organizations that result in inadequate delivery of mental health services. ${ }^{8,43,45}$

Instituting timely, effective, and guideline-driven treatment of each episode of depression to remission is critically important. Many patients do not fully respond or fail to respond to 
antidepressant treatment. ${ }^{46-48}$ The Sequenced Treatment Alternatives to Relieve Depression (STAR*D) trial found that 29\% to $46 \%$ of depressed patients failed to respond fully to antidepressant treatment of adequate dose and duration. An additional group of $12 \%$ to $15 \%$ had only a partial response, as measured by symptom severity. ${ }^{49} \mathrm{~A}$ patient with a Hamilton Depression Rating Scale (HDRS) rating $\geq 8$ after treatment had a high probability of relapse despite having improved during the trial. ${ }^{47,50}$ Patients with only partial response to antidepressants are more likely to have a relapse, impaired psychosocial functioning, increased risk of cardiac morbidity and mortality, and increased all-cause mortality. ${ }^{51}$

Discontinuation of antidepressant therapy has been found to result in rapid reemergence of symptoms and loss of any psychosocial gain, while maintenance therapy with a selective serotonin reuptake inhibitor (SSRI) for at least 4 months has been shown to protect against recurrence of chronic depression. ${ }^{52,53} \mathrm{~A}$ higher level of efficacy with first-line antidepressant medications can be achieved by optimizing dosage, offering concurrent cognitive behavioral therapy or interpersonal therapy, and recognizing when it is time to switch or augment therapies, according to best practice guidelines ${ }^{54}$ as well as applying the results of the STAR*D trial. ${ }^{48,55}$

In the STAR*D trial, patients who did not remit on citalopram, the first-line antidepressant, were then stratified and randomized to evaluate second-step treatments. ${ }^{48,55}$ Randomization was to sustained-release bupropion, extended-release venlafaxine, or sertraline. Depending on the antidepressant, the median time-toremission after initiation of the second antidepressant was from 4 to 6 weeks. Lack of response to 1 antidepressant as a first-line treatment did not imply that another antidepressant in the same class would not have efficacy. Both intraclass and interclass switches were found to be efficacious. ${ }^{56}$ Combining cognitive behavioral therapy with antidepressant treatment, either for the first-line or second-line treatment, not only improved remission rates, but also provided some relapse prevention..$^{57-63}$ Cognitive behavioral therapy has been shown to decrease an individual's cognitive reactivity to depressogenic stimuli, which additionally has been shown to provide some protection from recurrence of depression. . $^{59,64}$

\section{Clinical Presentation}

Major depressive disorder consists of a constellation of symptoms that traverse 3 domains: psychological, behavioral, and somatic (physical). The diagnostic criteria for major depression, as defined in the Diagnostic and Statistical Manual of Mental Disorders, Fourth Edition, Text Revision, are the same for women and men (Table 1) ${ }^{65}$ The presentation and course, however, can sometimes differ in women. Women may experience symptoms of atypical depression (e.g., hypersomnia, hyperphagia, carbohydrate craving, and evening mood exacerbation) and frequently have symptoms of anxiety, panic, and eating disorders. ${ }^{66}$

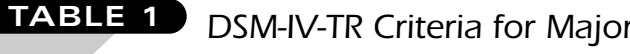 Depressive Episode}

A diagnosis of major depression disorder is based on the following list of symptoms and requires at least 1 or both symptoms from section $A$ and at least 5 of 9 symptoms overall.

A. At least 1 of the following abnormal moods, which significantly interfere with the person's life:

1. Abnormal depressed mood most of the day, nearly every day, for at least 2 weeks.

2. Abnormal loss of all interest and pleasure most of the day, nearly every day, for at least 2 weeks.

B. The following symptoms have been present during the same 2-week depressed period:

1. Appetite or weight disturbance, either

a. abnormal weight loss (when not dieting) or decrease in appetite, or

b. abnormal weight gain or increase in appetite.

2. Sleep disturbance, either abnormal insomnia or abnormal hypersomnia

3. Activity disturbance, either psychomotor agitation or retardation (observable by others).

4. Abnormal fatigue or loss of energy.

5. Feelings of worthlessness or inappropriate guilt.

6. Abnormal poor concentration or indecisiveness.

7. Recurrent thoughts of death (not just fear of dying) or suicide.

C. The symptoms are not due to a mood-incongruent psychosis.

D. There has never been a manic episode, a mixed episode, or a hypomanic episode.

E. The symptoms are not due to physical illness, alcohol, medication, or street drugs.

F. The symptoms are not due to normal bereavement.

If the patient is 18 years or younger, abnormal mood may manifest as irritability.

Note: Do not include symptoms that are clearly due to a general medical condition or mood-incongruent delusions or hallucinations.

Adapted from American Psychiatric Association (2000). ${ }^{65}$

DSM-IV-TR=Diagnostic and Statistical Manual of Mental Disorders, Fourth Edition, Text Revision.

\section{Psychological or Emotional Symptoms}

A major depressive episode is characterized by the psychological symptom of a persistent, diminished ability to experience pleasure. Patients appear sad or depressed and they are often pessimistic, believing that nothing will help them feel better. Anxiety symptoms are present in about 58\% of depressed outpatients. ${ }^{67}$ Irritability, indecisiveness, lack of interest or motivation, and excessive guilt are also common symptoms.

\section{Behavioral Symptoms}

Behavioral symptoms may manifest as cognitive symptoms or psychomotor disturbances. Patients may experience a decreased ability to concentrate, slowed thinking, and a poor memory for recent events - all of which contribute to reduced productivity. ${ }^{68}$ Psychomotor agitation, such as pacing or angry outbursts of shouting, may be present. Crying spells, interpersonal friction, 
social withdrawal, and avoidance of emotional intimacy may also be symptoms of major depressive disorder.

\section{Physical or Somatic Symptoms}

Patients who present with somatic symptoms as their predominant symptom of depression are often unaware that they suffer from depression. Data from the World Health Organization study of psychological problems in general health care found that $69 \%$ of participants who met criteria for depression approached their primary care clinician complaining of somatic symptoms alone. ${ }^{69}$ Kroenke et al. found a definitive correlation between the number of physical complaints and a diagnosis for depressive disorder. ${ }^{70}$ Chronic fatigue, which interferes with the ability to perform normal daily tasks, is a common somatic complaint in major depressive disorder. Pain, especially headache, often accompanies fatigue. Sleep disturbances and appetite disturbances, including decreased appetite or increased appetite and weight gain, may be present. Other somatic symptoms include gastrointestinal or cardiovascular complaints, muscle tension, or loss of sexual interest (Table 2).

\section{The Mood Disorders Continuum}

While major depressive disorder is considered 1 of the most common types of depression, depression should be thought of as part of a disease continuum that includes mood disorders and comorbidities such as anxiety disorders, all of which influence quality of life. The importance of early and accurate diagnosis is ideal for providing optimal treatment, clearly identifying patient triggers, diagnosing risk for future episode(s), and preventing further morbidity.

\section{Minor Depression/Depressive Spectrum Disorder}

Persistence of depressive mood symptoms for at least 2 weeks, but not otherwise meeting criteria for dysthymic disorder or major depressive disorder, is called minor depression or depressive spectrum disorder. ${ }^{71}$ It is common, and affects about $10 \%$ to $24 \%$ of the population over a lifetime. ${ }^{3}$ Depression spectrum disorders appear to cause functional impairment similar to that seen with other mood disorders ${ }^{72,73}$ and may have ramifications for long-term risk for development or recurrence of major depression..$^{74,75}$

\section{Dysthymic Disorder}

Dysthymic disorder is a chronic low-grade depression or depressed mood for at least 2 years, for most of the day, for more days than not, and includes any 2 of the following symptoms:

- Poor appetite or overeating

- Insomnia or hypersomnia

- Low energy or fatigue

- Low self-esteem

- Poor concentration or difficulty making decisions

- Feelings of hopelessness
Lifetime prevalence rates of dysthymic disorder are about $8 \%$ for women and about 5\% for men. ${ }^{76}$ Although dysthymic disorder is a chronic illness, it has an excellent recovery rate of about $74 \% .{ }^{67}$ However, the relapse rate of $71 \%$ is high, with the majority of relapses generally occurring within 3 years of recovery ${ }^{67}$ In many ways, dysthymic disorder is a more persistent condition than a non-chronic major depressive episode, particularly with respect to duration of symptomatology. Research indicates that $75 \%$ of patients with dysthymic disorder have exacerbations that meet criteria for major depressive disorder, and $95 \%$ of dysthymic disorder patients suffered a major depressive disorder during their lifetimes. ${ }^{77,78}$ Dysthymic disorder represents 36\% of patients in mental health settings. ${ }^{79}$

\section{Depressive Disorders and Comorbid Anxiety}

Comorbidity between generalized anxiety disorder (GAD) and dysthymic disorder or major depressive disorder is common. The presence of GAD has been found to significantly increase the risk of a subsequent depressive disorder. ${ }^{80}$ Patients who have comorbid GAD and a mood disorder often present with somatic symptoms, and these patients do not necessarily perceive their anxiety or mood problems as being connected to those symptoms. ${ }^{81}$ Similar to depression prevalence, anxiety disorders are also about 2 to 3 times more common in women than in men. ${ }^{82}$ When women experience depression, they are twice as likely to experience depression with anxious and somatic symptoms. Three fourths of patients with GAD will develop an episode of major depression in their lifetime. ${ }^{83}$

\section{Dregnancy, Breast-feeding, Menstrual Cycle, Seasonal Change, and the Menopausal Transition \\ Depression During Pregnancy}

The prevalence rate for depression in pregnant women is about $14 \% .{ }^{84}$ Factors such as history of depression or PMDD, younger age, limited social support, living alone, greater number of children, marital conflict, and ambivalence about pregnancy increase the risk of depression during pregnancy and the postpartum period. ${ }^{66}$ For women who develop depression during pregnancy the decision to treat depression requires thoughtful consideration of the risks and benefits as well as the treatment options. The use of medication during pregnancy remains a controversial and complicated issue, yet maternal anxiety and stress during the pregnancy appear to predict adverse pregnancy outcomes. ${ }^{85}$ Despite the frequency of depression in pregnant women, information to guide patients and physicians through the process of considering treatment during pregnancy is limited. ${ }^{84}$

\section{Depression During the Postpartum Period}

Postpartum depression is a major health issue for many women from diverse cultures. It is fairly common with a prevalence rate of about $13 \% .{ }^{86}$ Symptoms are somewhat different in women who have depression outside of the postpartum time period. Whereas 
non-postpartum depression is associated with sad mood and suicidal ideation, postpartum depression can be associated in some women with the psychomotor symptoms of restlessness and agitation, as well as impaired concentration and impaired decision making. ${ }^{87}$ If they are mild, mood changes postpartum are referred to as "postpartum blues." Postpartum blues are characterized by labile mood, tearfulness, and irritability. If the blues last longer than 2 weeks, the patient should be evaluated for postpartum depression.

The risk of postpartum depression is increased in women with pregravid depression, a history of PMDD during pregnancy, negative life events during pregnancy, and an inadequate social support system. ${ }^{66}$ Treatment of postpartum depression should take into consideration that many antidepressants readily cross into breast milk, and so the risks and benefits of taking antidepressants while breast-feeding should be evaluated in each patient to determine what is best for that patient and her child. If postpartum depression is not treated, risks increase for impaired maternal-child bonding, poor self-care, and newborn neglect. ${ }^{86}$

\section{Premenstrual Dysphoric Disorder}

PMDD is identified by somatic and emotional symptoms, which begin or worsen with luteal onset and resolve in the early follicular phase. About 3\% to $8 \%$ of women are affected by PMDD. ${ }^{15}$ Functional impairment is present and severe, and mood symptoms predominate. A history of PMDD is a risk factor for major depressive disorder. Up to $60 \%$ of those women with premenstrual dysphoria will have suffered or will suffer an episode of major depression. ${ }^{88-92}$ The probability of a woman with lifelong PMDD suffering a major depressive episode is high, as is the probability of her having had such an episode before middle age. ${ }^{93}$

\section{Seasonal Affective Disorder}

Seasonal affective disorder (SAD) meets criteria for major depression but occurs only in the winter months. ${ }^{94}$ The disorder is present in $0.4 \%$ to $2.7 \%$ of the population. ${ }^{94-96} \mathrm{~A}$ high comorbidity exists between SAD and PMDD. SAD and PMDD have common symptoms, and in 1 study, $46 \%$ of the women diagnosed with SAD also had a diagnosis of PMDD during the summer. ${ }^{97}$ The most common symptoms of SAD include a depressed mood, profound lack of energy, hypersomnia, hyperphagia, carbohydrate craving, and weight gain. Treatments include light therapy, medications, and psychotherapy.

\section{Depression Associated With the Menopausal Transition}

The perimenopausal transition is a time of increasing vulnerability for depressive episodes, with or without a history of a mood disorder. ${ }^{98-101}$ Freeman et al. found an increased likelihood of depressive symptoms during the transition to menopause and a decreased likelihood after menopause. ${ }^{20}$ A later study of women with no history of depression found that depressive symptoms increased during the transition to menopause

\section{TABLE 2 Common Physical Complaints in Depression ${ }^{66,69,70}$}

- Fatigue/loss of energy

- Insomnia

- Weight loss or gain: loss of or increase in appetite

- Dizziness/palpitations

- Gastrointestinal symptoms: abdominal cramping, bloating, heartburn, diarrhea, and/or constipation

- Numbness

- Bodily aches and pain/fibromyalgia: backache, chest pain, chronic joint pain, limb pain, headache, etc.

- Loss of sexual desire

compared with premenopause. ${ }^{101}$ Premenstrual symptoms in early perimenopausal women (aged 36-44 years) and an early natural menopause (before age 40) have been found to increase a woman's risk of mood problems. Longitudinal studies have found an association between increased risk of mood disorders in the menopausal transition and a history of depressed mood or depression, including postpartum depression and premenstrual syndrome, ${ }^{102}$ SLEs or life events viewed as undesirable, ${ }^{102-107}$ and identifiable stressors. ${ }^{108,109}$ Psychosocial difficulties were found in these studies to increase a midlife-aged woman's risk for mood problems during perimenopause. These psychosocial difficulties include a poor lifestyle (e.g., smoking), ${ }_{101}^{101}$ little exercise, ${ }^{110}$ difficulty paying for the basic necessities, ${ }^{111,112}$ lower educational level, ${ }^{111}$ health problems (e.g., comorbidities), ${ }^{106,113,114}$ lack of a partner, and single parenting. ${ }^{115}$

There is a strong relationship between the occurrence of hot flashes (e.g., vasomotor symptoms) and mood disorders. Women experiencing hot flashes have higher rates of depression regardless of prior incidence of depression. ${ }^{22}$ In longitudinal studies, vasomotor and somatic symptoms have consistently been found to increase risk of mood problems. ${ }^{104,116-118}$ Among women aged 35 to 52 years, greater anxiety and more depressed mood were both significantly associated with hot flashes. ${ }^{119}$ Hot flashes and the associated sleep disturbances can contribute to fatigue, irritability, personal embarrassment in public settings, and feelings of anxiety or lack of control.

Hot flashes vary in intensity, frequency, and duration. When women experience hot flashes, most (35\%) will experience them for 1 to 2 years, while 29\% will experience hot flashes for 3 to 5 years. However, up to $10 \%$ of women will experience hot flashes for 11 or more years. ${ }^{120,121}$ About 30\% of all perimenopausal women experience hot flashes too infrequently to count, $30 \%$ experience several per day, and 30\% experience hot flashes between few and several per day. ${ }^{120,122}$ The prevalence of hot flashes and night sweats in women aged 45 to 55 years has been estimated to occur in about $10 \%$ of premenopausal women, $32 \%$ of perimenopausal women, and $40 \%$ of naturally menopausal women. ${ }^{123}$ Yet $60 \%$ of women with depression 
were found in 1 study to experience hot flashes and night sweats. ${ }^{124}$ Additionally, women have been found to underreport their experience of hot flashes and night sweats. ${ }^{125}$

Estrogen augmentation to antidepressant treatment has been used in menopausal women to treat depressive episodes that have been refractory to complete remission without this augmentation. ${ }^{126-130}$ These studies found varying degrees of additive improvement with the concurrent treatment with estrogen. It should be noted, however, that these studies were either a pilot, ${ }^{126}$ small, ${ }^{127,130,131}$ and/or preliminary. ${ }^{129}$ One larger study ${ }^{132}$ and another preliminary study ${ }^{133}$ did not find an improvement with estrogen augmentation. In a recent study comparing 2 groups of surgically menopausal women suffering hot flashes and depressive symptoms, those women on lowdose estrogen therapy plus the SSRI fluvoxamine $50 \mathrm{mg}$ per day were significantly more likely to experience a decrease in the frequency of hot flashes and a lessening of depressive symptoms than were women on low-dose estrogen therapy only. ${ }^{134}$ Estrogen treatment is not yet considered a first-line treatment for major depression experience in perimenopause, either as monotherapy or as augmentation treatment.

\section{Summary}

Women are at risk for a wide range of depressive and anxiety disorders and have a particular risk of mood disorders associated with their menstrual cycle, seasonality, and menopause. While the majority of women do not experience mood and anxiety disorders during their lifetime, a significant minority do. The cumulative effect of childhood SLEs and premenopausal mood and anxiety disorders place women who experience them at an increased risk for a symptomatic menopause and a recurrence of mood and anxiety disorders throughout their later life.

Menopausal somatic symptoms such as hot flashes increase the risk of depression during the menopausal transition, and depression increases the risk of hot flashes. The importance of collaborative depression care within the managed care setting, with the timely diagnosis and treatment of depression throughout a woman's lifetime, should not be underestimated. Early and consistent interventions in the clinical setting using operationalized non-somatic therapies, such as cognitive behavioral therapy, interpersonal group therapy, and mindfulness-based therapies, are all crucial to increasing these women's abilities to prevent further depressive episodes. These therapies will also help them maintain their well-being and provide some prevention of future depressive episodes by decreasing heightened sensitivity to negative appraisal/depressogenic reactions to SLEs. The prevalence of depression, its psychosocial and medical consequences, and the worsening course of depression without treatment highlight the critical importance of early detection and effective treatment strategies in the managed care setting.

\section{FUNDING}

The authors of this supplement are thankful to the Wyeth Pharmaceuticals Continuing Medical Education Grant Office for its support of this satellite symposium, Shrinking Health Care Disparities in Women: The Depression Dilemma, at the 19th Annual Meeting of the Academy of Managed Care Pharmacy, San Diego, California, April 11-14, 2007. This article is based on the lecture by Jeanne L. Alexander at that symposium. The honoraria supporting her participation in this symposium as well as the writing of this article were both donated to the Alexander Foundation for Women's Health, a 501(c)(3) nonprofit organization (www.afwh.org), to which she donates her time and has not been remunerated for her efforts.

\section{DISCLOSURES}

Jeanne L. Alexander has no relevant financial relationships.

\section{REFERENCES}

1. Kouzis AC, Eaton WW. Emotional disability days: prevalence and predictors. Am J Public Health. 1994;84(8):1304-07.

2. Wells KB, Stewart A, Hays RD, et al. The functioning and well-being of depressed patients. Results from the Medical Outcomes Study. JAMA 1989;262(7):914-19.

3. Kessler RC, McGonagle KA, Swartz M, Blazer DG, Nelson CB. Sex and depression in the National Comorbidity Survey. I: Lifetime prevalence, chronicity and recurrence. J Affect Disord. 1993;29(2-3):85-96.

4. National Institute of Mental Health. The impact of mental illness on society. Available at: http://masterdocs.com/fact_sheet_files/pdf/ mental_illness.pdf. Accessed June 3, 2007.

5. Ohayon M, Schatzberg A. Fine-tuning our diagnosis and treatment of depression. Editorial. J Psychiatr Res. 2006;40(4):281-82.

6. Goldman LS, Nielsen NH, Champion HC. Awareness, diagnosis, and treatment of depression. J Gen Intern Med. 1999;14:569-80.

7. Rentsch D, Dumont P, Borgacci S, et al. Prevalence and treatment of depression in a hospital department of internal medicine. Gen Hosp Psychiatry. 2007;29:25-31.

8. Grypma L, Haverkamp R, Little S, Unutzer J. Taking an evidence-based model of depression care from research to practice: making lemonade out of depression. Gen Hosp Psychiatry. 2006;28:101-07.

9. Parker G, Hadzi-Pavlovic D. Is the female preponderance in major depression secondary to a gender difference in specific anxiety disorders? Psychol Med. 2004;34:461-70.

10. Piccinelli M, Wilkinson G. Gender differences in depression. Critical review. Br J Psychiatry. 2000;177:486-92.

11. Wilhelm K, Roy K, Mitchell P, et al. Gender differences in depression risk and coping factors in a clinical sample. Acta Psychiatr Scand. 2002;106:45-53

12. Gladstone GL, Parker GB, Mitchell PB, Malhi GS, Wilhelm K, Austin MP Implications of childhood trauma for depressed women: an analysis of pathways from childhood sexual abuse to deliberate self-harm and revictimization. Am J Psychiatry. 2004;161:1417-25.

13. Kendler KS, Gatz M, Gardner CO, Pedersen NL. A Swedish national twin study of lifetime major depression. Am J Psychiatry. 2006;163:109-14.

14. Kuehner C. Gender differences in unipolar depression: an update of epidemiological findings and possible explanations. Acta Psychiatr Scand. 2003;108:163-74.

15. Steiner M, Pearlstein T, Cohen LS, et al. Expert guidelines for the treatment of severe PMS, PMDD, and comorbidities: the role of SSRIs J Women's Health. 2006;15:57-69. 
16. Kendler KS, Gardner CO, Prescott CA. Toward a comprehensive development model for major depression in women. Am J Psychiatry. 2002;159:1133-45.

17. Orstavik RE, Kendler KS, Czajkowski N, Tambs K, ReichbornKjennerud T. Genetic and environmental contributions to depressive personality disorder in a population-based sample of Norwegian twins. J Affect Disord. 2007;99:181-89.

18. Kendler KS, Kuhn J, Prescott CA. The interrelationship of neuroticism, sex, and stressful life events in the prediction of episodes of major depression. Am J Psychiatry. 2004;161:631-36.

19. Kendler KS, Kuhn JW, Prescott CA. Childhood sexual abuse, stressful life events, and risk of major depression in women. Psychol Med. 2004;34:1475-82.

20. Freeman EW, Sammel MD, Liu L, Gracia CR, Nelson DB, Hollander L. Hormones and menopausal status as predictors of depression in women in transition to menopause. Arch Gen Psychiatry. 2004;61:62-70.

21. Keller MB, Lavori PW, Mueller TI, et al. Time to recovery, chronicity, and levels of psychopathology in major depression: a five-year prospective follow-up of 431 subjects. Arch Gen Psychiatry. 1992;49:809-16.

22. Keller MB, Boland RJ. Implications of failing to achieve successful long-term maintenance treatment of recurrent unipolar major depression. Biol Psychiatry. 1998;44:348-60.

23. Kessler RC, Berglund P, Demler O, et al. The epidemiology of major depressive disorder: results from the National Comorbidity Survey Replication (NCS-R). JAMA. 2003;289(23):3095-105.

24. Kendler KS, Thornton LM, Gardner CO. Genetic risk, number of previous depressive episodes, and stressful life events in predicting onset of major depression. Am J Psychiatry. 2001;158:582-86.

25. Kendler KS, Thornton LM, Gardner CO. Stressful life events and previous episodes in the etiology of major depression in women: an evaluation of the "kindling" hypothesis. Am J Psychiatry. 2000;157:1243-51.

26. Corruble E, Falissard B, Gorwood P. Life events exposure before a treated major depressive episode depends on the number of past episodes. Eur Psychiatry. 2006;21(6):364-66.

27. Kendler KS, Gardner CO, Gatz M, Pedersen NL. The sources of co-morbidity between major depression and generalized anxiety disorder in a Swedish national twin sample. Psychol Med. 2007;37:453-62.

28. Bouma EM, Ormel J, Verhulst FC, Oldehinkel AJ. Stressful life events and depressive problems in early adolescent boys and girls: the influence of parental depression, temperament and family environment. J Affective Disord. June 13, 2007. Epub ahead of print.

29. Cervilla J, Molina E, Rivera M, et al. The risk for depression conferred by stressful life events is modified by variation at the serotonin transporter 5HTTLPR genotype: evidence from the Spanish PREDICT-Gene cohort. Mol Psychiatry. Advance online publication; March 27, 2007. Available at: www.nature.com/mp/journal/v12/n8/pdf/400198la.pdf.

30. Kim J, Stewart R, Kim S, et al. Interactions between life stressors and susceptibility genes (5-HTTLPR and BDNF) on depression in Korean elders. Biol Psychiatry. May 3, 2007;62(5):423-28. Epub ahead of print.

31. Stein M, Schork N, Gelernter J. Gene-by-environment (serotonin transporter and childhood maltreatment) interaction for anxiety sensitivity, an intermediate phenotype for anxiety disorders. Neuropsychopharmacology. Advance online publication; April 25, 2007.

32. Kaufman J, Yang B-Z, Douglas-Palumberi H, et al. Brain-derived neurotrophic factor-5-HTTLPR gene interactions and environmental modifiers of depression in children. Biol Psychiatry. 2006;59:673-80.

33. Wichers MC, Myin-Germeys I, Jacobs N, et al. Evidence that moment-to-moment variation in positive emotions buffer genetic risk for depression: a momentary assessment twin study. Acta Psychiatr Scand. 2007;115(6):451-57.
34. Safford SM, Alloy LB, Abramson LY, Crossfield AG. Negative cognitive style as a predictor of negative life events in depression-prone individuals: a test of the stress generation hypothesis. J Affect Disorder. 2007;99:147-54.

35. Kendler K, Thornton L, Prescott C. Gender differences in the rates of exposure to stressful life events and sensitivity to their depressogenic effects. Am J Psychiatry. 2001;158:587-93.

36. Reichenberg A, Maccabe J. Feeling the pressure: work stress and mental health. Psychol Med. May 3, 2007;1:1-2. Epub ahead of print.

37. Santavirta N, Solovieva S, Theorell T. The association between job strain and emotional exhaustion in a cohort of 1,028 Finnish teachers. Br J Educ Psychol. 2007;77(pt 1):213-28.

38. Melchior M, Berkman N, Niedhammer I, Zins M, Goldberg M The mental health effects of multiple work and family demands. A prospective study of psychiatric sickness absence in the French GAZEL study. Soc Psychiatry Psychiatr Epidemiol. May 24, 2007;42(7):573-82. Epub ahead of print.

39. Maclean H, Glynn K, Ansara D. Multiple roles and women's mental health in Canada. BMC Women's Health. 2004;4(suppl 1):S3-S7.

40. Greenberg P, Leong SA, Birnbaum H. Costs of depression: current assessment and future directions. Expert Rev Pharmacoeconomics Outcomes Res. 2001;1:69-76

41. Kim-Cohen J, Moffitt TE, Taylor A, Pawlby SJ, Caspi A. Maternal depression and children's antisocial behavior. Arch Gen Psychiatry. 2005;62:173-81

42. Remick R. Diagnosis and management of depression in primary care: a clinical update and review. CMAJ. 2002;167:1253-60.

43. VonKorff M, Katon W, Unutzer J, Wells K, Wagner E. Improving depression care barriers, solutions, and research needs. J Fam Pract. 2001;50:530-31.

44. Gilbody S, Whitty P, Grimshaw J, Thomas R. Educational and organizational interventions to improve the management of depression in primary care: a systematic review. JAMA. 2003;289:3145-51.

45. Wells K, Sherbourne C, Schoenbaum M, et al. Impact of disseminating quality improvement programs for depression in managed primary care: a randomized controlled trial. JAMA. 2000;283:212-20.

46. Paykel E. Cognitive therapy in relapse prevention in depression. Int J Neuropsychopharmacol. 2006;20:1-6.

47. Rush A, Kraemer H, Sackeim H, et al. Report by the ACNP Task Force on response and remission in major depressive disorder. Neuropsychopharmacology. 2006;31:1841-53.

48. Thase ME, Friedman ES, Biggs MM, et al. Cognitive therapy versus medication in augmentation and switch strategies as second-step treatments: a STAR*D report. Am J Psychiatry. 2007;164:739-52.

49. Fava M, Davidson KG. Definition and epidemiology of treatmentresistant depression. Psychiatr Clin North Am. 1996;19:179-200.

50. Paykel ES, Ramana R, Cooper Z, et al. Residual symptoms after partial remission: an important outcome in depression. Psychol Med. 1995;25:1171-80.

51. Keller MB. Past, present and future directions for defining optimal treatment outcome in depression. JAMA. 2003;289:3152-60.

52. Keller MB, Kocsis JH, Thase ME, et al. Maintenance phase efficacy of sertraline for chronic depression. JAMA. 1998;280:1665-72.

53. Kocsis JH, Schatzberg A, Rush J, et al. Psychosocial outcomes following long-term, double blind treatment of chronic depression with sertraline vs placebo. Arch Gen Psychiatry. 2002;59:723-28.

54. American Psychiatric Association. Practice guidelines for the treatment of patients with major depressive disorder, 2nd ed. April 2000. In: American Psychiatric Association, Practice Guidelines for the Treatment of Psychiatric Disorders. Compendium 2004. Arlington, VA: American Psychiatric Association; 2004. 
55. Wisniewski SR, Fava M, Trivedi MH, et al. Acceptability of second-step treatments to depressed outpatients: a STAR*D report. Am J Psychiatry. 2007; 164:753-60

56. Rush AJ, Trivedi MH, Wisniewski SR, et al. Bupropion-SR, sertraline, or venlafaxine-XR after failure of SSRIs for depression. N Engl J Med. 2006;354:1231-42.

57. Hollon SD, Stewart MO, Strunk D. Enduring effects for cognitive behavior therapy in the treatment of depression and anxiety. Annu Rev Psychol. 2006;57:285-315.

58. Teasdale JD, Segal ZV, Williams JM, et al. Prevention of relapse/ recurrence in major depression by mindfulness-based cognitive therapy. J Consult Clin Psychol. 2000;68(4):615-23.

59. Fresco DM, Segal ZV, Buis T, Kennedy S. Relationship of posttreatment decentering and cognitive reactivity to relapse in major depression. J Consult Clin Psychol. 2007;75:447-55.

60. Vittengl JR, Clark LA, Dunn TW, Jarrett RB. Reducing relapse and recurrence in unipolar depression: a comparative meta-analysis of cognitive behavioral therapy's effects. J Consult Clin Psychol. 2007;75:475-88.

61. Jarrett RB, Vittengl JR, Doyle K, Clark LA. Changes in cognitive content during and following cognitive therapy for recurrent depression: substantial and enduring, but not predictive of change in depressive symptoms. J Consult Clin Psychol. 2007;75:432-46.

62. Kingston T, Dooley B, Bates A, Lawlor E, Malone K. Mindfulness-based cognitive therapy for residual depressive symptoms. Psychol Psychother. 2007;80(pt 2):193-203.

63. Kashner TM, Henley SS, Golden RM, Rush AJ, Jarrett RB. Assessing the preventive effects of cognitive therapy following relief of depression: a methodological innovation. J Affect Disord. May 15, 2007. Epub ahead of print.

64. Segal ZV, Kennedy S, Gemar M, et al. Cognitive reactivity to sad mood provocation and the prediction of depressive relapse. Arch Gen Psychiatry. 2006;63:749-55.

65. American Psychiatric Association. Diagnostic and Statistical Manual of Mental Disorders, Fourth Edition, Text Revision. Washington DC: American Psychiatric Association; 2000.

66. Bhatia SC, Bhatia SK. Depression in women: diagnostic and treatment considerations. Am Fam Physician. 1999;60:225-40.

67. Merikangas KR, Zhang H, Avenevoli S, Acharyya S, Neuenschwander M, Angst J. Longitudinal trajectories of depression and anxiety in a prospective community study. Arch Gen Psychiatry. 2003;60:993-1000.

68. Stewart W, Ricci J, Chee E, Hahn S, Morganstein D. Cost of lost productive work time among US workers with depression. JAMA. 2003;289:3135-44

69. Simon GE, VonKorff M, Piccinelli M, Fullerton C, Ormel J. An international study of the relation between somatic symptoms and depression. N Engl J Med. 1999;341:1329-35.

70. Kroenke K, Spitzer RL, Williams JB, et al. Physical symptoms in primary care: predictors of psychiatric disorders and functional impairment. Arch Fam Med. 1994;3:774-97.

71. Rowe SK, Rapaport MH. Classification and treatment of sub-threshold depression. Current Opinion in Psychiatry. 2006;19:9-13.

72. Jaffe A, Froom J, Galambos N. Minor depression and functional impairment. Arch Fam Med. 1994;3:1081-86.

73. Rapaport MH, Judd LL, Schettler PJ, et al. A descriptive analysis of minor depression. Am J Psychiatry. 2002;159:637-43.

74. Cuijpers P, de Graaf R, van Dorsselaer S. Minor depression: risk profiles, functional disability, health care use and risk of developing major depression. J Affect Disord. 2004;79:71-79.
75. Cuijpers P, Smit F. Subthreshold depression as a risk indicator for major depressive disorder: a systematic review of prospective studies. Acta Psychiatr Scand. 2004;109:325-331.

76. Kessler RC, McGonagle KA, Zhao S, et al. Lifetime and 12-month prevalence of DSM-III-R psychiatric disorders in the United States. Results from the National Comorbidity Survey. Arch Gen Psychiatry. 1994;51:8-19.

77. Keller MB, Klein DN, Hirschfeld RM, et al. Results of the DSM-IV mood disorders field trial. Am J Psychiatry. 1995;152:843-49.

78. Klein DN, Shankman SA, Rose S. Ten-year prospective follow-up study of the naturalistic course of dysthymic disorder and double depression. Am J Psychiatry. 2006;163:872-80.

79. Markowitz JC, Moran ME, Kocsis JH, Frances AJ. Prevalence and comorbidity of dysthymic disorder among psychiatric outpatients. J Affect Disord. 1992;24:63-71.

80. Wittchen HU, Kessler RC, Pfister H, Lieb M. Why do people with anxiety disorders become depressed? A prospective-longitudinal community study. Acta Psychiatrica Scandinavica, Supplementum. 2000;406:14-23.

81. Grant BF, Hasin DS, Stinson FS, et al. Prevalence, correlates, co-morbidity, and comparative disability of DSM-IV generalized anxiety disorder in the USA: results from the National Epidemiologic Survey on Alcohol and Related Conditions. Psychol Med. 2005;35:1747-59.

82. Kessler RC, Keller MB, Wittchen HU. The epidemiology of generalized anxiety disorder. Psychiatr Clin North Am. 2001;24:19-39.

83. Fricchione G. Generalized anxiety disorder. N Engl J Med. 2004;351:675-82

84. Wisner KL, Gelenberg AJ, Leonard H, Zarin D, Frank E. Pharmacologic treatment of depression during pregnancy. JAMA. 1999;282:1264-69.

85. Hendrick V, Altshuler L, Strouse T, Grosser S. Postpartum and nonpostpartum depression: differences in presentation and response to pharmacologic treatment. Depress Anxiety. 2000;11:66-72.

86. Dennis CL. Psychosocial and psychological interventions for prevention of postnatal depression: systematic review. BMJ. 2005;331:15-23.

87. Bernstein IH, Rush AJ, Yonkers K, et al. Symptom features of postpartum depression: are they distinct? Depress Anxiety. 2006;1-7.

88. DeJong R, Rubinow DR, Roy-Byrne P, et al. Premenstrual mood disorder and psychiatric illness. Am J Psychiatry. 1985;142:1359-61.

89. Endicott J. The menstrual cycle and mood disorders. J Affect Disord. 1993;29:193-200.

90. Stout A, Steege J, Blazer D, George L. Comparison of lifetime psychiatric diagnoses in premenstrual syndrome clinic and community samples. J Nerv Ment Dis. 1986;174:517-22.

91. Yonkers K. The association between premenstrual dysphoric disorder and other mood disorders. J Clin Psychiatry. 1997;58:19-25.

92. Kim DR, Gyulai L, Freeman EW, Morrison MF, Baldassano C, Dubé B. Premenstrual dysphoric disorder and psychiatric co-morbidity. Arch Womens Ment Health. 2004;7:37-47.

93. Richards M, Rubinow D, Daly R, Schmidt P. Premenstrual symptoms and perimenopausal depression. Am J Psychiatry. 2006;163:133-37.

94. Levitt A, Boyle MH, Joffe RT, Baumal Z. Estimated prevalence of the seasonal subtype of major depression in a Canadian community sample. Can J Psychiatry. 2000;45:650-54.

95. Levitt AJ, Boyle MH. The impact of latitude on the prevalence of seasonal depression. Can J Psychiatry. 2002;47:361-67.

96. Blazer D, Kessler R, Swartz M. Epidemiology of recurrent major and minor depression with a seasonal pattern. The National Comorbidity Survey. Br J Psychiatry. 1998;172:164-67.

97. Praschak-Rieder N, Willeit M, Neumeister A, et al. Prevalence of premenstrual dysphoric disorder in female patients with seasonal affective disorder. J Affect Disord. 2001;63:239-42. 
98. Schmidt PJ, Haq N, Rubinow DR. A longitudinal evaluation of the relationship between reproductive status and mood in perimenopausal women. Am J Psychiatry. 2004;161:2238-44.

99. Schmidt PJ, Murphy JH, Haq N, Rubinow DR, Danaceau MA. Stressful life events, personal losses, and perimenopause-related depression. Arch Womens Ment Health. 2004;7:19-26.

100. Cohen L, Soares C, Vitonis A, Otto M, Harlow B. Risk for new onset of depression during the menopausal transition: the Harvard study of moods and cycles. Arch Gen Psychiatry. 2006;63:385-90.

101. Freeman EW, Sammel MD, Lin H, Nelson DB. Associations of hormones and menopausal status with depressed mood in women with no history of depression. Arch Gen Psychiatry. 2006;63:375-82.

102. Woods NF, Mariella A, Mitchell ES. Patterns of depressed mood across the menopausal transition: approaches to studying patterns in longitudinal data. Acta Obste. Gynecol Scan. 2002;81:623-32.

103. Hunter M, Battersby R, Whitehead M. Relationships between psychological symptoms, somatic complaints and menopausal status. Maturitas. 1986;8(3):217-28.

104. Hunter M. The south-east England longitudinal study of the climacteric and postmenopause. Maturitas. 1992;14(2):117-26.

105. Avis NE, Brambilla D, McKinlay SM, Vass K. A longitudinal analysis of the association between menopause and depression. Results from the Massachusetts Women's Health Study. Ann Epidemiol. 1994;4:214-20.

106. Kaufert P, Gilbert P, Tate R. The Manitoba Project: a re-examination of the link between menopause and depression. Maturitas. 1992;14:143-55.

107. Lock M, Kaufert P, Gilbert P. Cultural construction of the menopausal syndrome: the Japanese case. Maturitas. 1988;10:317-32.

108. Amick BC 3rd, Kawachi I, Coakley EH, et al. Relationship of job strain and iso-strain to health status in a cohort of women in the United States. Scand J Work Environ Health. 1998;24:54-61.

109. Cheng Y, Kawachi I, Coakley EH, Schwartz J, Colditz G. Association between psychosocial work characteristics and health functioning in American women: prospective study. BMJ. 2000;320:1432-36.

110. Dennerstein L, Dudley EC, Hopper JL, Guthrie JR, Burger HG. A prospective population-based study of menopausal symptoms. Obstet. Gynecol. 2000;96:351-58.

111. Bromberger JT, Assmann SF, Avis NE, et al. Persistent mood symptoms in a multiethnic community cohort of pre- and perimenopausal women. Am J Epidemiol. 2003;158:347-56.

112. Bromberger JT, Harlow S, Avis N, Kravitz HM, Cordal A. Racial/ethnic differences in the prevalence of depressive symptoms among middle-aged women: the Study of Women's Health Across the Nation (SWAN). Am J Public Health. 2004;94:1378-85.

113. McKinlay SM, Brambilla DJ, Posner JG. The normal menopause transition. Maturitas. 1992;14:103-15.

114. Woods NF, Mitchell ES. Anticipating menopause: observations from the Seattle Midlife Women's Health Study. Menopause. 1999;6:167-73.

115. Walters V. Stress, anxiety and depression: women's accounts of their health problems. Soc Sci Med. 1993;36:393-402.

116. Bromberger JT, Matthews KA. A longitudinal study of the effects of pessimism, trait anxiety, and life stress on depressive symptoms in middle-aged women. Psychol Aging. 1996;11:207-13.

117. Dennerstein L, Burrows GD, Hyman GJ, Sharpe K. Hormone therapy and affect. Maturitas. 1979;1:247-59.
118. Baker A, Simpson S, Dawson D. Sleep disruption and mood changes associated with menopause. J Psychosom Res. 1997;43:359-69.

119. Schmidt PJ, Rubinow DR. Menopause-related affective disorders: a justification for further study. Am J Psychiatry. 1991;148:844-52.

120. Feldman BM, Voda A, Gronseth E. The prevalence of hot flash and associated variables among perimenopausal women. Res Nurse Health. 1985;8(3):261-68

121. Berg G, Gottwall T, Hammar M, Lindgren R. Climacteric symptoms among women aged 60-62 in Linkoping, Sweden in 1986. Maturitas. 1988;10:193-99

122. Guthrie J, Dennerstein L, Burger H, Hopper J. Hot flushes, menstrual status and hormone levels in a population-based sample of midlife women. Obstet Gynecol. 1996;88:437-42.

123. Dennerstein L, Brown JB, Gotts G, Morse CA, Farley TM, Pinol A. Menstrual cycle hormonal profiles of women with and without premenstrual syndrome. J Psychosom Obstet Gynaecol. 1993;14:259-68

124. Judd LL, Paulus MP, Wells KB, Rapaport MH. Socioeconomic burden of subsyndromal depressive symptoms and major depression in a sample of the general population. Am J Psychiatry. 1996;153:1411-17.

125. Carpenter JS, Monahan PO, Azzouz F. Accuracy of subjective hot flush reports compared with continuous sternal skin conductance monitoring. Obstet Gynecol. 2004;104(6):1322-26.

126. Morgan M, Cook I, Rapkin A, Leuchter A. Neurophysiologic changes during estrogen augmentation in perimenopausal depression. Maturitas. 2007;56:54-60

127. Morgan ML, Cook IA, Rapkin AJ, Leuchter AF. Estrogen augmentation of antidepressants in perimenopausal depression: a pilot study. J Clin Psychiatry. 2005;66:774-80.

128. Rasgon N, Dunkin J, Fairbanks L, et al. Estrogen and response to sertraline in postmenopausal women with major depressive disorder: a pilot study. J Psychiatr Res. 2007;41:338-43.

129. Rasgon NL, Altshuler LL, Fairbanks LA, et al. Estrogen replacement therapy in the treatment of major depressive disorder in perimenopausal women. J Clin Psychiatry. 2002;63(suppl 7):45-48

130. Soares CN, Poitras JR, Prouty J, et al. Efficacy of citalopram as a monotherapy or as an adjunctive treatment to estrogen therapy for perimenopausal and postmenopausal women with depression and vasomotor symptoms. J Clin Psychiatry. 2003;64:473-79.

131. Joffe H, Groninger H, Soares CN, Nonacs R, Cohen LS. An open trial of mirtazapine in menopausal women with depression unresponsive to estrogen replacement therapy. J Womens Health Gend Based Med. 2001;10:999-1004.

132. Amsterdam J, Garcia-Espana F, Fawcett J, et al. Fluoxetine efficacy in menopausal women with and without estrogen replacement. J Affect Disord. 1999;55(1):11-17.

133. Schneider LS, Small GW, Clary CM. Estrogen replacement therapy and antidepressant response to sertraline in older depressed women. Am J Geriatr Psychiatry. 2001;9:393-99.

134. Nagata H, Nozaki M, Nakano H. Short-term combinational therapy of low-dose estrogen with selective serotonin re-uptake inhibitor (fluvoxamine) for oophorectomized women with hot flashes and depressive tendencies. J Obstet Gynaecol Res. 2005;31:107-14. 